INT. J. REMOTE SENSING, 1999, VOL. 20, NO. 13, 2683-2688

\title{
Remote detection of a tonal anomaly in an area of hydrocarbon microseepage, Tucano basin, north-eastern Brazil
}

\author{
RAIMUNDO ALMEIDA-FILHO \\ National Institute for Space Research-INPE, Caixa Postal 515, \\ São José dos Campos-SP, Brazil \\ FERNANDO P. MIRANDA \\ Petrobras/CENPES, Cidade Universitária, Ilha do Fundão, Q-7, \\ Rio de Janeiro-RJ, Brazil \\ and TADASHI YAMAKAWA \\ Earth Resources Satellite Data Analysis Center-ERSDAC 3-12-1, \\ Kachidoki Chuo-Ku, Tokyo 104, Japan
}

(Received 30 September 1998; in final form 16 December 1998)

\begin{abstract}
Mapping of a tonal anomaly in an area of hydrocarbon microseepage was possible using a Landsat-Thematic Mapper false-colour composite consisting of $\mathrm{TM} 2 / 3, \mathrm{TM} 4 / 3$ and of the difference $\mathrm{TM} 2 / 3-\mathrm{TM} 4 / 3$, displayed as red, green and blue, respectively. In this false-colour composite, green and yellow express variations in the vegetation cover, whereas hues of magenta are related to terrain conditions representing bleached materials, which occur close to the centre of a soil gas anomaly. Simultaneous occurrence of anomalous soil gas values with magnetic and radioactive minerals suggests that a reducing environment associated with the microseepage phenomenon created the bleached materials, identified as a tonal anomaly in the enhanced TM image.
\end{abstract}

\section{Introduction}

The leakage of hydrocarbon and associated fluids to the surface is responsible for a number of chemical alterations in rocks and soils that overlay oil and gas reservoirs. The reducing environment created by microseepage phenomenon can convert limonitic minerals to the ferrous state, resulting in bleaching of red beds. Additionally, feldspars can be converted to clay minerals (kaolinite, illite, chlorite). Other mineralogical changes can take place in such an environment, such as the formation of calcite, pyrite, uranium, and certain magnetic iron oxides and sulphides (Donovan 1974, Matthews 1986, Segal and Merin 1989, Schumacher 1994). Some of these microseepage-induced minerals exhibit diagnostic spectral features that allow their remote identification. Ferric-iron materials shows a fall-off in reflectance from the near-infrared to visible that permits the discrimination between ferric-iron rich and ferric-iron depleted materials. Clay minerals and carbonates exhibit diagnostic absorption spectral features centred at $2.20 \mu \mathrm{m}$ and $2.35 \mu \mathrm{m}$, respectively (Hunt 1977). Based on the presence of these particular mineral assemblages and resulting 
soil-vegetation features, remote sensing techniques have been used to detect microseepage sites in areas of hydrocarbon accumulations (e.g. Patton and Manwaring 1984, Simpson et al. 1989, Segal and Merin 1989).

In this study we evaluate the possibility that altered areas (bleaching) induced by hydrocarbon microseepage, could be discriminated from background terrain in Landsat-Thematic Mapper (TM) images. Our analysis covered a soil gas anomaly previously identified by the Brazilian National Oil Co. (PETROBRAS).

\section{The study area}

The study area is located in the Tucano basin, in the state of Bahia, north-eastern Brazil. The region (figure 1) has a semi-arid climate with average annual precipitation under $500 \mathrm{~mm}$, mean annual temperatures around $28^{\circ} \mathrm{C}$ and a dry savannah-like vegetation cover (locally called caatinga) characterised by small thorny trees with a profusion of thin stems, reduced number of leaves and frequent presence of members of the Cactaceae family. Visual inspection of aerial photographs obtained in 1981 reveals a history of human activity and physical disturbance within the study area, with cleared areas and regrowth of the vegetation cover.

The Tucano basin is part of the Recôncavo-Tucano-Jatobá rift, a series of northsouth elongated half grabens, about $600 \mathrm{~km}$ long by $90 \mathrm{~km}$ wide, formed during the early stages of the South Atlantic opening in the Early Cretaceous (Milani and Davison 1988). Sedimentary sequences of the rifting phase are represented by lacustrine and deltaic shales and sandstones, followed by fluvial sandstones. Post-rift Aptian fluvial and alluvial sandstones, limestones and conglomerates of the Marizal Formation unconformably cover these sequences. Outcrops of the post-rift rocks in the study area consist of weathered and oxidised fine-grained quartzose whitish-toreddish sandstones with thin lenses of cherty limestone. Whitish to brownish sandy soils occur throughout the area.

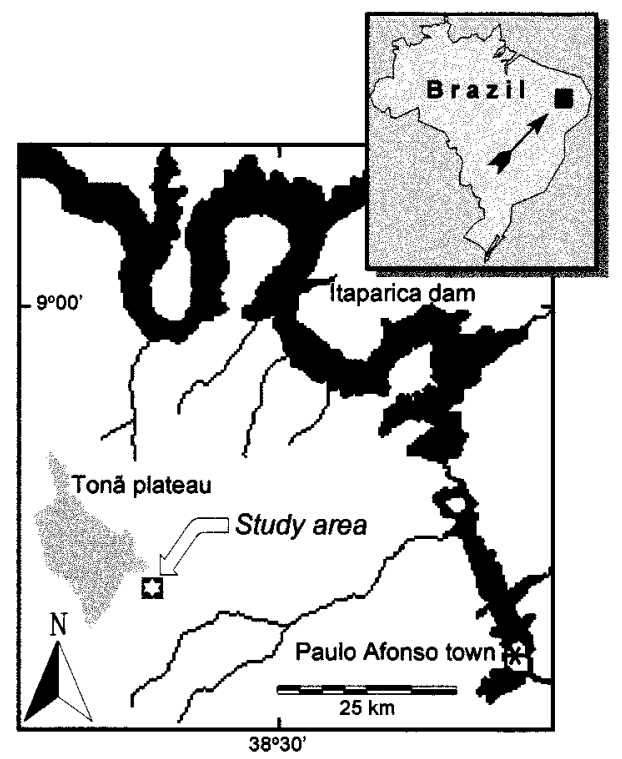

Figure 1. Location of the study area. 


\section{Field data acquisition}

As part of a regional exploration program, PETROBRAS carried out a geochemistry soil gas survey for methane, ethane, propane, butane, and pentane, covering an area of approximately $1500 \mathrm{~km}^{2}$ in the northern part of the Tucano basin (Babinski et al. 1993). Hydrocarbon soil gas (ethane to pentane) yielded an arithmetic mean value of $3.61 \mathrm{ppm}$, assumed as the regional background (methane was not considered due to its possible biogenic origin). The highest anomaly indicated from these data, located in the south-eastern border of the Tonã plateau, was selected as a test site, covering an area of approximately $2.5 \times 2.5 \mathrm{~km}$ (figure 1 ).

Six 500-metre spaced soil gas determinations were acquired along a profile across the study area in October, 1995. Field data also included 100-metre spaced measurements of radioactivity intensity (total count) and magnetic susceptibility . For gamma radiation measurements, a portable scintillometer was used with accuracy of $\pm 10 \%$ for energy above $50 \mathrm{KeV}$. Magnetic susceptibility measurements were obtained using a kappameter with measurement ranges automatically switched to 9.99 , 99.9, or $999\left(\times 10^{-3}\right)$ SI units.

Figure 2 compares results of the radiometric $(a)$, magnetic $(b)$, and soil gas $(c)$ data in the study area. Soil gas data reach the maximum value at station 11 (51.9 ppm), followed by higher values of magnetic susceptibility and higher radioactivity intensities. Such a
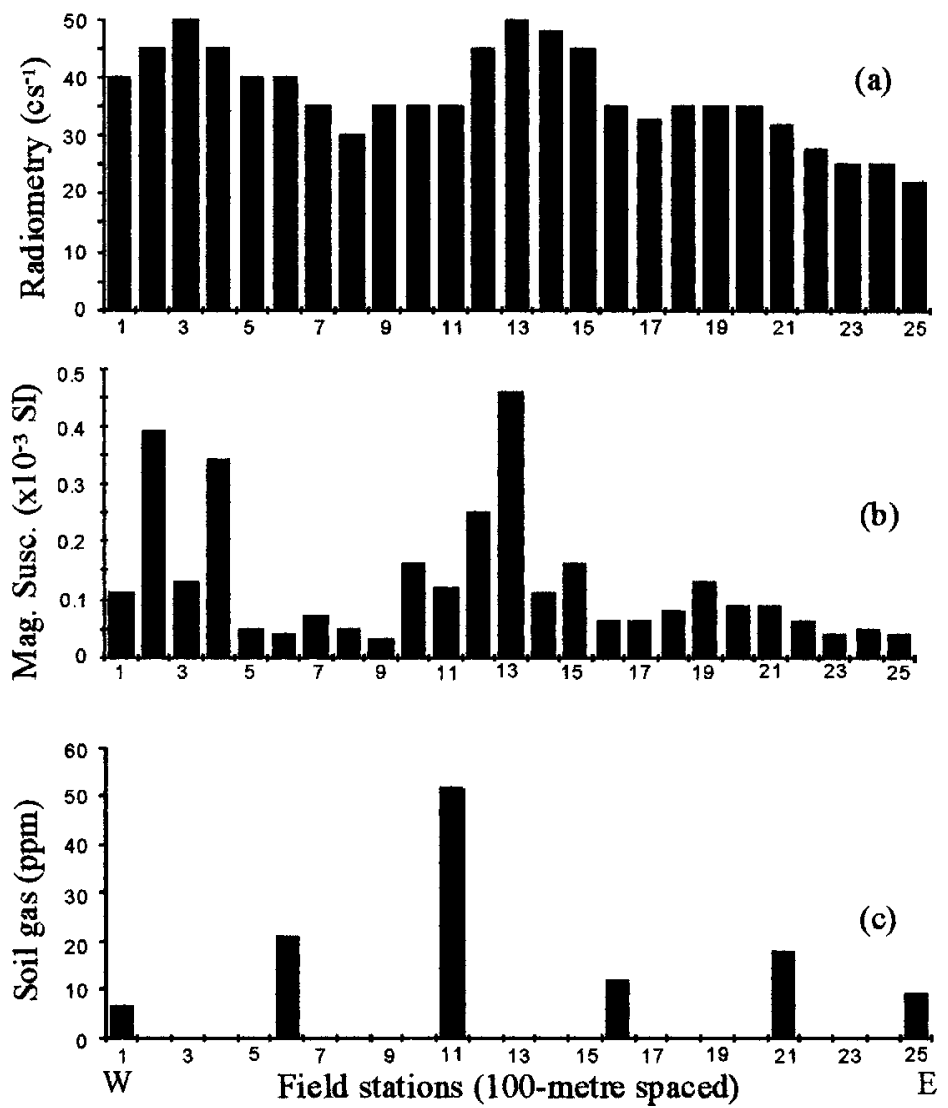

Figure 2. Field data acquired in a profile across the study area: (a) radioactivity intensity, (b) magnetic susceptibility, and (c) soil gas (sum of ethane to pentane). Field stations are indicated as a dotted line in figure 4). 
simultaneous occurrence of soil gas with magnetic and radioactive minerals suggests that reducing agents favoured precipitation of these minerals, attesting the action of a reducing environment, essential for the occurrence of the bleaching phenomenon.

\section{Image processing and analysis}

Landsat-TM images were examined in order to investigate the possibility that altered areas induced by microseepage phenomena (bleached materials), could be detected under the physiographic conditions of the study area. The only cloud-free available Landsat-TM scene (path 216, row 66) was acquired on 7 October 1987, under solar elevation and azimuth angles of $56^{\circ}$ and $86^{\circ}$, respectively. Images were corrected for atmospheric scattering (visible bands) using shaded areas as reference. To adjust the greyscale ranges, a linear contrast stretch was applied to the data between the upper and lower $2 \%$ of the histograms. In addition, they were also referenced to the Universal Transverse Mercator co-ordinate system, through a least squares first-degree polynomial rectification algorithm based on control points extracted from a topographic map (1:100 000 scale). This procedure yielded a geometric accuracy equivalent to 0.7 pixel.

A number of digitally enhanced images, including contrast stretched false-colour composites and a natural colour composite, failed to reveal any colour variations that could be confidently associated with microseepage-related phenomena. More conclusive results were obtained through the analysis of band-ratio images. Owing to the fact that ferric-iron rich rocks exhibit a fall-off in reflectance from $0.8 \mu \mathrm{m}$ towards shorter wavelengths (Hunt, 1977), the ratio of TM2 $(0.52-0.60 \mu \mathrm{m})$ and TM3 $(0.63-0.69 \mu \mathrm{m})$ bands can be used to estimate the distribution of limonitic materials on the surface, which are indicated by low TM2/3 ratios. In contrast, ferriciron poor materials yield high TM2/3 ratios. Since vegetation also yields high TM $2 / 3$ (higher response in green and lower in red wavelengths), the presence of healthy vegetation cover was estimated through the ratio of the TM4 $(0.76-0.90 \mu \mathrm{m})$ and TM3 bands. Areas yielding high TM2/3 and low TM4/3 ratios may be assigned to ferric-iron poor materials, expressed as subtle grey shades in ratio images.

Scatterplots of these ratio images provide a graphical demonstration of the discrimination of terrain features in the study area. Figure $3(a)$ is the scatterplot of
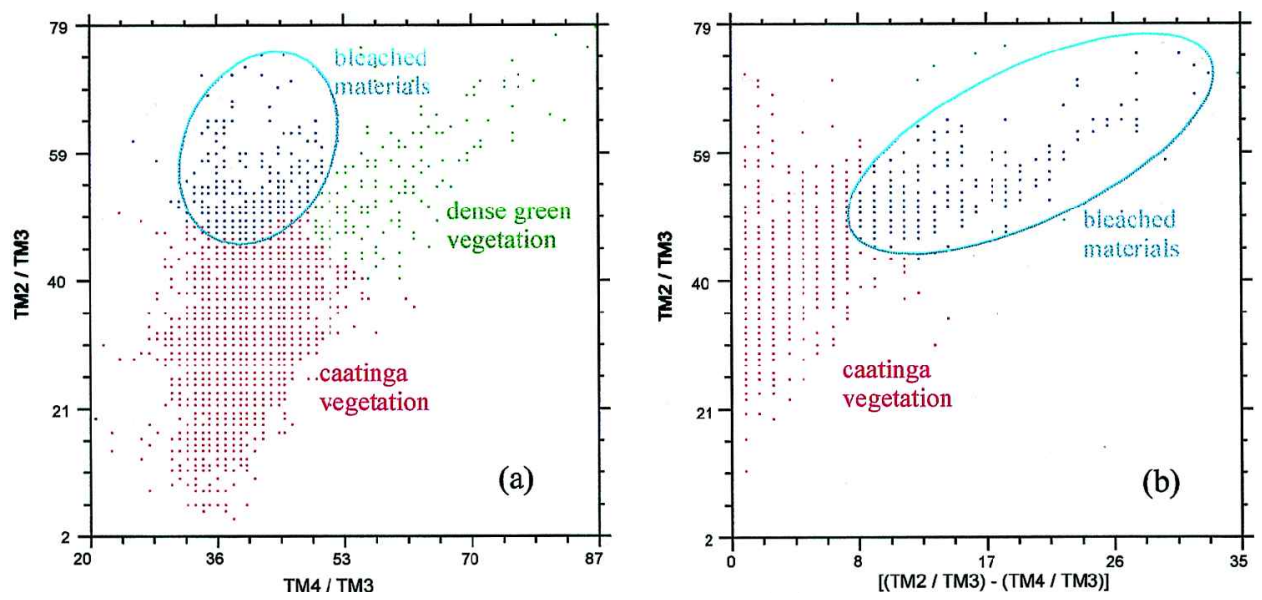

Figure 3. Scatterplots showing groups of pixels in the Landsat-TM ratios, assigned as distinct soil-vegetation assemblages and terrain conditions in the study area. 


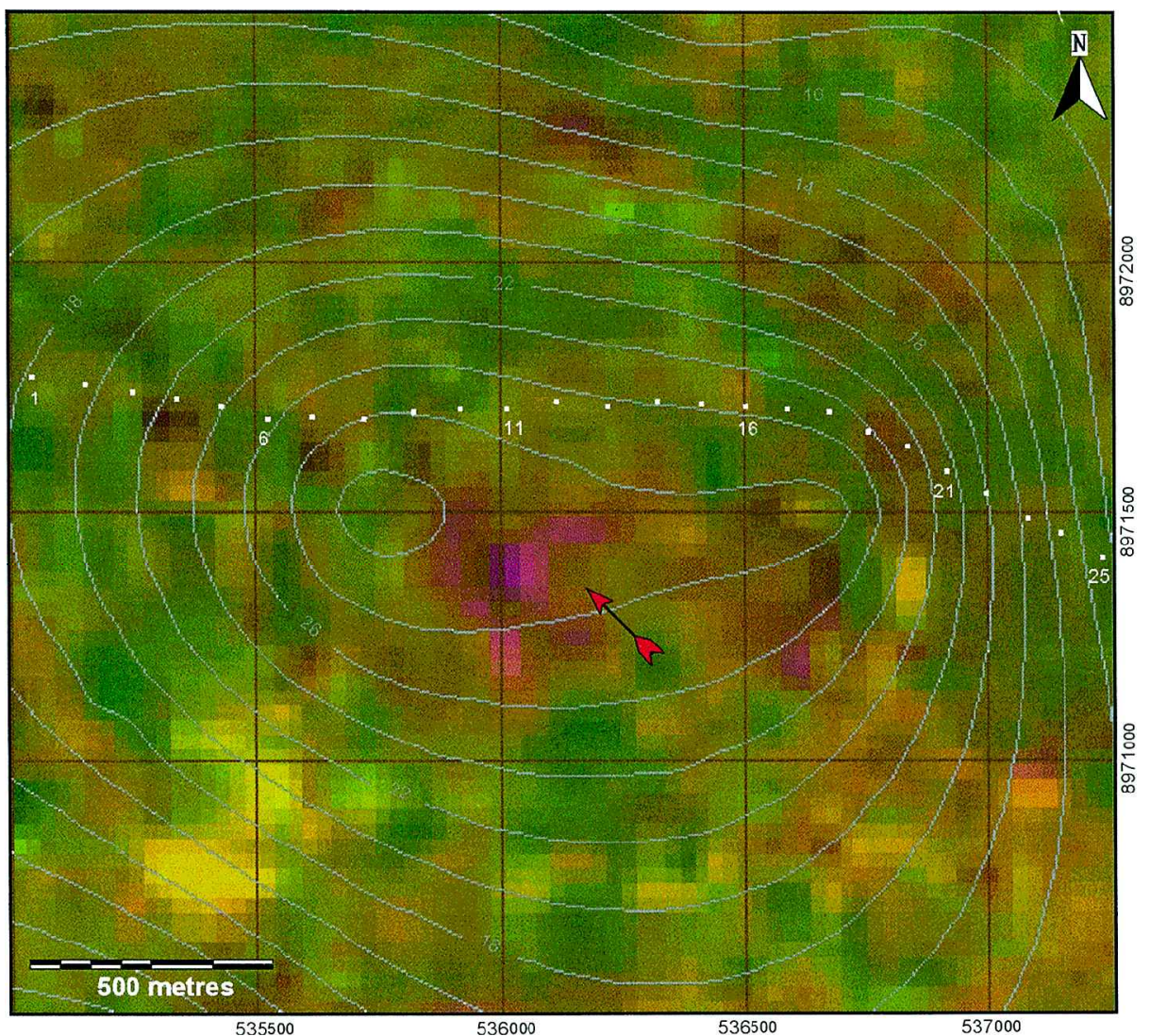

Figure 4. Band ratio false colour composite [TM2/3 (R), TM4/3 (G), TM2/3-TM4/3 (B)] indicating in hues of magenta areas of bleached materials (arrow). Contour lines show soil gas (ethane to pentane) values ( $\mathrm{ppm})$. Stations of field data acquisition are also indicated on the image.

the ratio TM2/3 versus the ratio TM4/3, showing three groups of pixels assigned to the main distinct soil-vegetation assemblages in the study area, represented by bleached materials, dense green vegetation and dry caatinga vegetation. Pixels associated with areas of bleached materials are better distinguished in the scatterplot of the ratio TM2/3 versus the ratio difference (TM2/3-TM4/3), shown in figure $3(b)$.

Since the human eye is much more sensitive to colour hues than to grey tones, a false-colour composite consisting of TM2/3, TM4/3 and of the difference TM2/3TM4/3, displayed as red, green and blue, respectively, shows these subtle grey tones as colour variations (figure 4). In this band ratio false-colour composite, green and yellow hues (high responses in TM2/3 and TM4/3 ratios) express variations in the vegetation cover, whereas hues of magenta (high TM2/3 ratio and high TM2/3-TM4/3 ratio difference) are related to terrain conditions representing bleached materials (indicated by the arrow in the colour composite).

To compare the results of the image enhancement with soil gas data distribution, kriging was used to interpolate geochemistry data (including nineteen additional soil gas data available over a larger region of $5 \mathrm{~km} \times 5 \mathrm{~km}$ encompassing the study area). The result is shown as contour lines ( $\mathrm{ppm}$ ) on the ratio false colour composite (figure 4). According to these data the tonal anomaly is located close to the core of the soil gas anomaly defined by the contour lines. 
Field check showed that the tonal anomaly in the Landsat TM ratio colour composite results from an in situ cover of angular cobbles (silicified materials) on the terrain surface. Petrographic analysis indicates they constitute laminated or nodular bioclastic limestone (resulting from the vital activities of ostracods), totally replaced by microgranular chalcedony. Rocks outside the tonal anomaly constitute ferruginous, non-fossilised carbonate duricrust. Thin sections showed they are constituted mainly by laminated micrites, partly converted to dolomite, including also calcite, hematite, and goethite.

\section{Conclusions}

The mapping of bleached materials in an area of hydrocarbon microseepage was made possible using band-ratio techniques focused on iron oxide absorption features in TM2 relative to TM3 bands. By including a vegetation index (TM4/3) and the difference between these two ratios (TM2/3 minus TM4/3) it was possible to compensate for vegetation cover differences, thereby enhancing a tonal anomaly on the image in the microseepage area. While our study has focused on a single site in the state of Bahia, Brazil, it is reasonable to expect that this technique or variations from it, could be successful in identifying subtle areas of surface bleaching in similar semi-arid regions of the world. Because the spectral signatures of bleaching can arise from other chemical environments (e.g. hydrothermal alteration) and even in certain primary deposits, the interpretation must be made within the context of available geological data.

\section{Acknowledgments}

INPE, PETROBRAS, ERSDAC, and FAPESP (Research Foundation of São Paulo State) supported this work. The authors thank their colleagues Benedito Silva, Gilmar Bueno, Massami Ootake and Nélson Tesch, for their help during the field data acquisition. Maria D. Carvalho and Jarbas V. Guzzo were responsible for petrographic and paleontologic analysis. We also thank Peter Szatmari, Chris Elvidge and anonymous reviewers for constructive criticism of the manuscript.

\section{References}

Babinski, N. A., Santos, R. C. R., Bueno, G. V., Guimarães, M. F., Freire, A. F. M., Gouveia, C. A. S., Almeida, M. F., and Volpan, A. G., 1993, Prospecção geoquímica de superfície (gasometria e microbiologia de petróleo) na bacia de Tucano Norte. CENPES/SINTEP/MCT, 650-15.106, Brazilian Oil Co., Brazil.

Donovan, T. J., 1974, Petroleum microseepage at Cement, Oklahoma-evidence and mechanism. American Association of Petroleum Geologists Bulletin, 5, 429-446.

Hunt, G. R., 1977, Spectral signatures of particulate minerals in the visible and near infrared. Geophysics, 42, 501-513.

Matthews, M. D., 1986, Effects of hydrocarbon leakage on Earth surface materials. In Proceedings of the Symposium on Unconventional Methods in Exploration for Petroleum and Natural Gas. Dallas, USA, 1986 (Dallas: S. M. U. Press), pp. 27-44.

Milani, E. J., and Davison, I., 1988, Basement control and transfer tectonics in the RecôncavoTucano-Jatobá Rift, Northeast Brazil. Tectonophysics, 154, 41-70.

Patton, K. H., and Manwaring, M. S., 1984, Evaluation of a Landsat-derived tonal anomaly for hydrocarbon microseepage, Southwest Kansas. In Proceedings of the Thematic Conference Remote Sensing for Exploration Geology, Colorado Springs, USA, 1984 (Ann Arbor: Environmental Research Institute of Michigan), pp. 441-450.

Schumacher, D., 1994, Hydrocarbon-induced alteration of soils and sediments. In: Hydrocarbon migration and its near-surface expression, edited by D. Schumacher and M. A. Abrams (Tulsa: AAPG Memoir 66), pp. 71-89.

Segal, D. B., and Merin, I. S., 1989, Successful use of Landsat Thematic Mapper data for mapping hydrocarbon microseepage-induced mineralogic alteration, Lisbon Valley, Utah. Photogrammetric Engineering and Remote Sensing, 55, 1137-1145.

Simpson, C. J., Wilford, J. R., Maciais, L. F., and Korsch, R. J., 1989, Satellite detection of natural hydrocarbon seepage: Palm Valley gas field, Amadeus Basin, Central Australia. The APEA Journal, 29, 196-211. 